\title{
Stereotactic Body Radiotherapy for Idiopathic Subtricuspid Ventricular Arrythmia
}

\author{
Manuel Patete ${ }^{1}$, Ivo Rodriguez ${ }^{2}$, Rafael Herrera ${ }^{2}$, Dulce García ${ }^{1}$, Mikel Liñero ${ }^{1}$, Keren \\ Millan $^{1}$, Niorali Quintero ${ }^{1}$, Frank Aquino ${ }^{1}$, and Carlos D. Matos ${ }^{3}$ \\ ${ }^{1}$ Fundación Corazones Unidos \\ ${ }^{2}$ Clínica Abreu \\ ${ }^{3}$ Unidad Internacional de Arritmias
}

September 24, 2021

\begin{abstract}
Introduction: In cases of recurrent ventricular arrythmias (RVA) after radiofrequency ablation (RFA), stereotactic body radiotherapy (SBRT) using a single high dose of has emerged as an effective treatment. Methods And Results: SBRT was performed as treatment of an Idiopathic Subtricuspid Ventricular Arrythmia recurrent to RFA with progressive cardiac function deterioration despite the staggered use of antiarrhythmic drugs. No sedation was required, and the patient tolerated the procedure with no related complications. During post-procedural follow-up the arrhythmic density dropped from $33 \%$ to $1 \%$ in 90 days. Conclusions: SBRT can be an effective treatment for RVA that should be further investigated.
\end{abstract}

\section{Hosted file}

Stereotactic Body Radiotherapy for Idiopathic Subtricuspid Ventricular Arrythmia.pdf available at https://authorea.com/users/435702/articles/538543-stereotactic-bodyradiotherapy-for-idiopathic-subtricuspid-ventricular-arrythmia 